
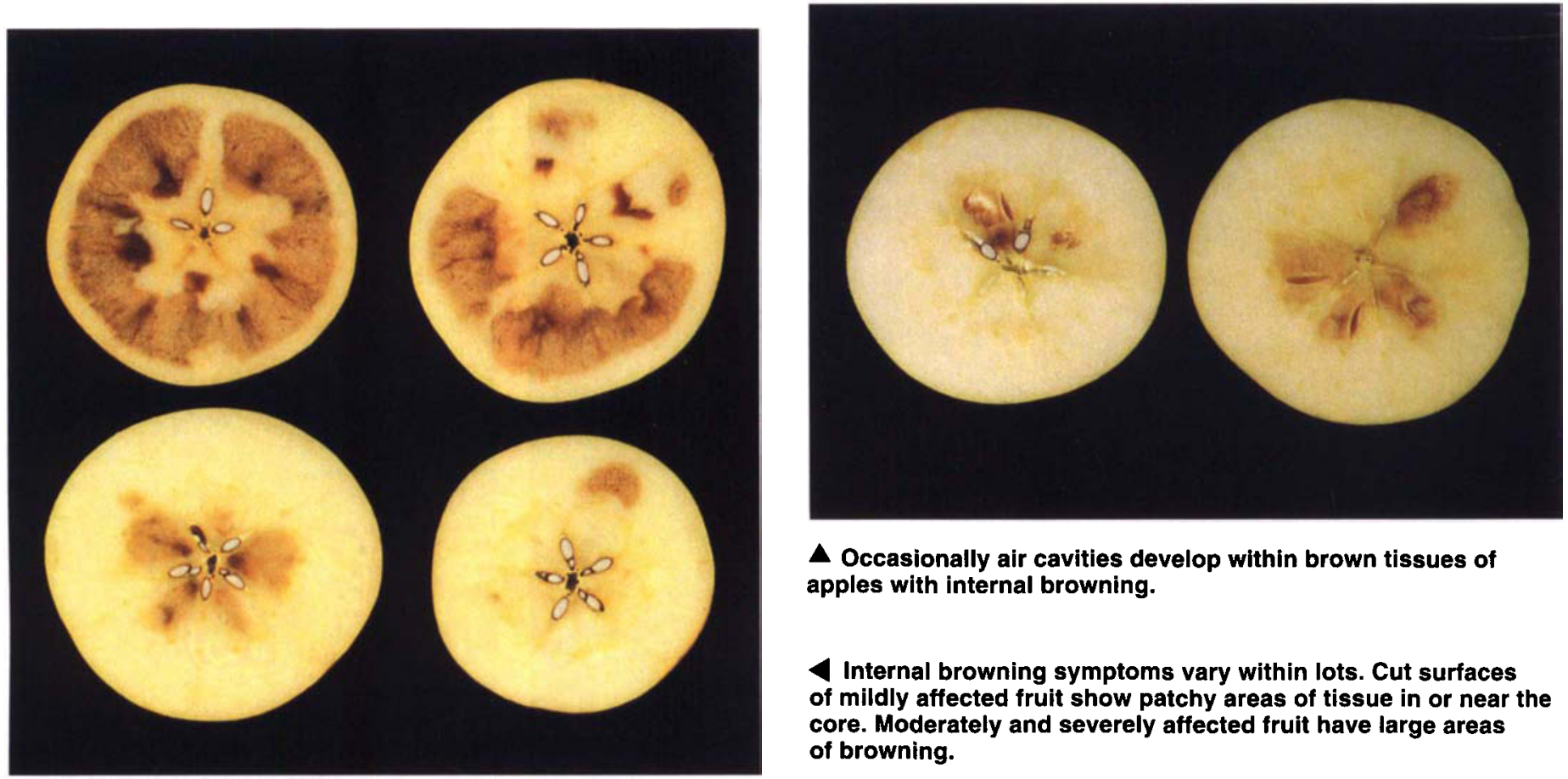

$\Delta$ Occasionally air cavities develop within brown tissues of apples with internal browning.

4 Internal browning symptoms vary within lots. Cut surfaces of mildly affected fruit show patchy areas of tissue in or near the core. Moderately and severely affected truit have large areas of browning.

\section{Late harvest, high $\mathrm{CO}_{2}$ storage increase internal browning of Fuji apples}

\author{
Joe Grant $\square$ Beth Mitcham $\square \quad$ Bill Biasi $\square \quad$ Steve Chinchiolo
}

In a 3-year study, internal browning of Fuji apples during postharvest storage varied from year to year, but was strongly affected each year by harvest timing and carbon dioxide concentration in storage atmospheres. Internal browning incidence and severity were low in fruit harvested within 180 days after bloom. Timely harvest and storage at $\mathrm{CO}_{2}$ levels below $0.5 \%$ are recommended to reduce losses from this disorder.

In the 15 years that Fuji apples have been grown commercially in California, apple growers and packers have quickly learned how to grow and market this premium quality dessert apple. California Fuji growers typi- cally conduct several sequential harvests over a 4-to-6-week period to optimize eating quality and external red color development. Firm, sweet and low in acid, Fuji apples may be successfully stored under controlled atmospheres (CA) at $32^{\circ} \mathrm{F}$ and $90 \%$ to $95 \%$ relative humidity as long as 9 months after harvest. Many preharvest and postharvest problems have been successfully resolved as Fuji apple acreage and production have increased, while some remain as challenges. Internal browning (IB), first observed in California during the winter marketing of Fuji apples from the 1991 harvest, remains a challenge.

In January 1992, packers observed that some lots of Fuji apples showed moderate to severe IB upon removal from CA storage. The disorder was greatest in large fruit from lateharvested lots. Because IB has been linked to advanced fruit maturity and elevated carbon dioxide $\left(\mathrm{CO}_{2}\right)$ levels during storage in pears and other apple varieties, handlers questioned whether fruit maturity and/or a failure to adequately monitor or control storage $\mathrm{CO}_{2}$ levels may have contributed to the IB problem for Fuji apples. Here we report results of studies conducted from 1992 through 1994, which evaluate the roles of harvest timing and $\mathrm{CO}_{2}$ levels during $\mathrm{CA}$ storage in development of this disorder.

The extent and intensity of patchy areas of brown flesh discoloration associated with IB vary among apples within a given lot. Fruit with low IB intensity typically have one to several small, tan to light-brown areas of affected tissue, often first appearing near or in the core. These brown areas increase in size, may merge and often become chocolate brown in color as symptoms become more severe. The margin between affected and normal tissue is smooth and distinct. In the most severely affected apples, the entire flesh may turn brown, with the exception of a thin layer of normal tissue just beneath the skin.

Externally, IB-affected fruit appear normal, making this defect virtually 
impossible to eliminate during packing-house sorting operations. The presence of even small amounts of IB may result in the downgrading or rejection of entire lots of fruit by produce buyers.

\section{Storage tests}

For all 3 years of the test, we used apples from a well-managed commercial Fuji apple orchard near Modesto with a history of IB. The orchard, planted in 1987, was standard Fuji on M111 rootstock, planted 10-feet-by-16feet. Soil was a deep, well-drained loamy sand with neutral to slightly alkaline $\mathrm{pH}$. The orchard was sprinkleirrigated with well water. Gross yields were 18.4, 35.4 and 15.3 tons per acre in 1992, 1993 and 1994, respectively.

In 1992 , we collected 160 to 180 fruit at random from bins during commercial harvests on September 21, and October 1, 12 and 27. These dates corresponded to $174,184,195$ and 210 days after bloom (DAB). To determine harvest maturity, we measured individual fruit firmness and tested for composite soluble solids and titratable acidity using 25 fruit harvested on each date.

Flesh firmness was measured using a

UC Firmness Tester fitted with a $7 / 16$-inch apple tip. Two readings (on opposing cheeks with skin removed) were made on each fruit. Soluble solids and acidity measurements were made on juice pressed from small longitudinal wedges cut from each of 25 fruit.

Fruit from each harvest were stored in a $36^{\circ} \mathrm{F}$ cold room until October 30 , three days following the last harvest. After sorting to remove blemished and defective fruit, fruit from each harvest were divided into four 30-fruit subsamples. These were stored at $32^{\circ} \mathrm{F}$ and $95 \%$ relative humidity in air $\left(0.03 \% \mathrm{CO}_{2}\right)$ or one of three controlled atmospheres with $2 \% \mathrm{O}_{2}$ and $0.4 \%$ $( \pm 0.1), 1.5 \%( \pm 0.1)$ or $3.0 \%( \pm 0.2) \mathrm{CO}_{2}$ provided by a flow-through system. Fruit were evaluated for internal browning after four months storage and five days in ambient air at $68^{\circ} \mathrm{F}$. To evaluate IB, we sliced fruit in half, perpendicular to the stem end, and visually inspected the two cut surfaces for signs of browning in the fruit flesh.
Fruit with IB were rated as having slight (1 to $10 \%$ ), moderate (11 to $41 \%$ ) or severe ( 41 to $100 \%$ ) symptoms according to the percentage of cut surfaces having brown discoloration.

In 1993, we harvested fruit on September 13 and 27 and October 11 and $25(169,183,197$ and $211 \mathrm{DAB})$ from six preselected trees in the orchard. In contrast to 1992, trees were left unpicked for the duration of our harvests, except for our own samples and a very light commercial color-picking on September 15. At each harvest, we picked 28 to 30 of the most visibly mature fruit, using ground color and red skin color as criteria, from each of the six trees.

When apples are harvested multiple times to optimize color, size and flavor, interior fruit - generally the least mature on the tree - is the last to be picked. Because packers had observed that late-harvested lots showed more IB, and these tend to consist of a large percentage of interior canopy fruit, we hypothesized that fruit from interior canopy locations might be more prone to IB than outer canopy fruit. Thus, we collected two samples of fruit on the last harvest date in 1993: one consisting of highly colored fruit from upper and outer canopy positions and one from interior portions of trees.

Individual fruit firmness and composite soluble solids and acidity determinations were made on 25 fruit harvested on each date, as in 1992. We also measured starch-to-sugar conversion of 25 apples using an iodinepotassium iodide solution. This solution turns starchy portions of the apple cortex blue, allowing the disappearance of starch to be monitored as apples mature. Ratings progress from 0 (immature, all of cortex and core starchy) to 6 (over-mature, starch gone from cortex and core).

On each harvest date, blemished and defective fruit were discarded, and 30 -fruit subsamples were placed into $32^{\circ} \mathrm{F}$ air or CA storage (same $\mathrm{O}_{2}$ and $\mathrm{CO}_{2}$ concentrations as 1992) for four months, held for five days in air at $68^{\circ} \mathrm{F}$, then evaluated for IB as in 1992.

In 1994, we repeated the sampling procedures of 1992 and 1993 in adjacent rows of the test orchard. In one

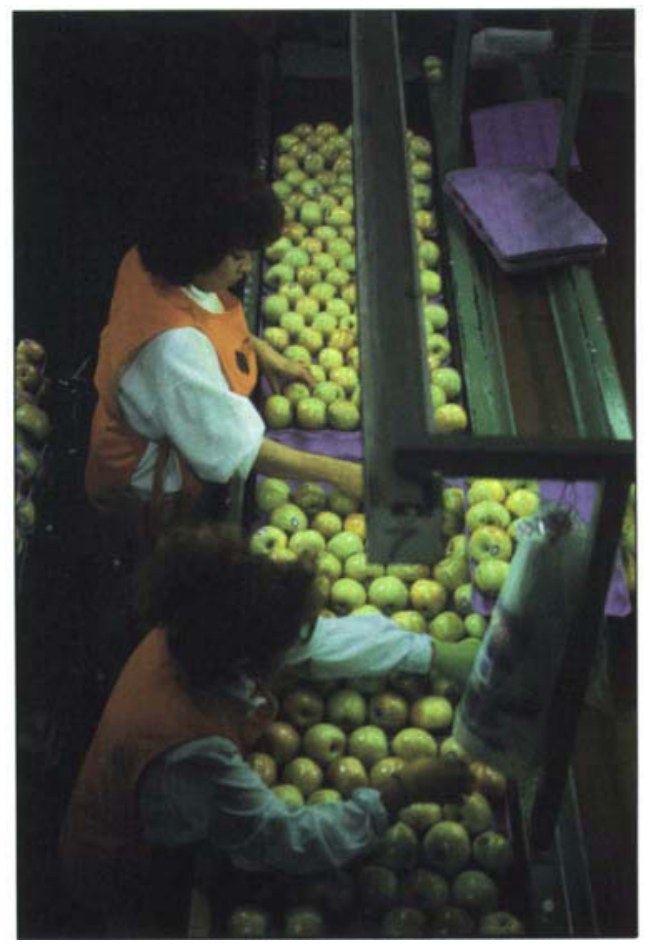

On the surface, internal browning-affected fruit appear normal, making this defect virtually impossible to eliminate during packing-house sorting.

row, we randomly collected 160 to 180 fruit from bins containing apples from approximately 20 preselected trees during each of four commercial harvests in the orchard. Fruit on 20 trees in the other row were not harvested except for 160 to 180 fruit sampled randomly on each harvest date for storage tests. Except for the first harvest (September 21 for the sampleharvested row and September 26 for the commercially harvested row), we sampled on the same dates for both rows: October 6 and 21, and November 1 . These dates corresponded to 175 or $180 \mathrm{DAB}$ for the first harvest, and 190, 205 and $216 \mathrm{DAB}$ for subsequent harvests. Fruit harvest evaluations, storage conditions and poststorage evaluations were the same in 1994 as 1993.

\section{Harvest evaluations}

None of the fruit evaluated at harvest in 1992 or 1993 had internal browning (data not shown). In 1994, however, we observed slight symptoms of IB in a small percentage of fruit during evaluations at harvest. In general, fruit firmness and acidity declined as the harvest season progressed each year, while starch disap- 
pearance scores and soluble solids concentrations increased (table 1).

\section{Storage test results}

In 1992, after storage in the various atmospheres, there was little or no IB in fruit from all but the latest harvest (fig. 1a). Air-stored fruit from this harvest had essentially no internal browning, and IB increased with $\mathrm{CO}_{2}$ concentration in $\mathrm{CA}$ (linear effect of $\mathrm{CO}_{2}$, $P<0.001$ ).

Internal browning incidence was lower in 1993 than 1992 (figs. 1a and 1b). Internal browning was low to nil in fruit stored in air, $0.4 \%$, or $1.5 \%$ $\mathrm{CO}_{2}$, but high in late-harvested fruit held in $3 \% \mathrm{CO}_{2}$. There was a significant linear increase in IB with increasing $\mathrm{CO}_{2}$ for each of the last two harvests $(P<0.001)$. IB was not significantly different between fruit from interior and exterior canopy positions. Apparently, interior canopy origin did not contribute to the greater IB observed in late-harvested 1992 fruit, unless the prior removal of exterior fruit - typical in commercial harvests but not our 1993 sampling - somehow predisposed interior fruit to IB. Rather,

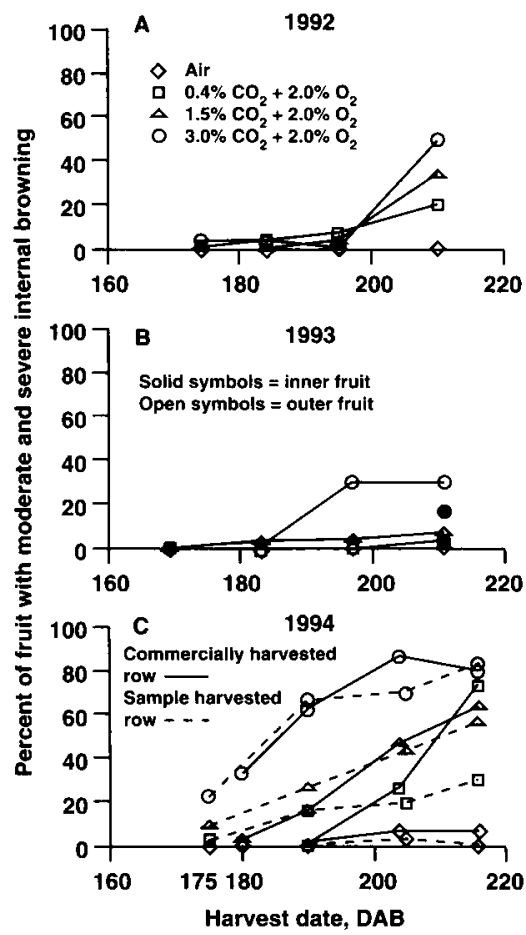

Fig. 1 Internal browning varied greatly among years, storage atmospheres and harvest dates. we believe these data support a relationship between advanced fruit maturity and greater susceptibility to IB in storage.

In 1994, IB incidence and severity were greater than in the two previous years (fig. 1c). As in 1992, IB incidence was low in early-harvested fruit stored in air or low $\mathrm{CO}_{2} \mathrm{CA}$, but increased markedly with harvest date $(P<0.001)$ and $\mathrm{CO}_{2}$ level in $\mathrm{CA}(P<0.001$ for each harvest individually and averaged over all harvests). Harvest method - sampled versus commercial - did not significantly affect IB incidence, whether analyzed by individual storage atmosphere or over all atmospheres. These findings were surprising since we expected sampleharvested trees to yield fruit of progressively greater maturity and IB susceptibility than commercially harvested trees.

We often observed small dry cavities, up to 0.5 inch in size, within brown areas of IB fruit in 1993 and 1994, but not in 1992. Air cavities form when dead tissue shrinks, and are symptomatic of $\mathrm{CO}_{2}$ injury in pears and other apple varieties.
The year-to-year variations in internal browning at our test site were consistent with commercial packers' observations of IB incidence during the 3 years of this study. In 1994, many packers reported significant levels of IB in apples from orchards previously free of this disorder. Apparently, unknown preharvest factors cause fruit to be more prone to IB in some years and orchards than others. Orchard and/or environmental factors that might predispose fruit to IB development are currently under study.

\section{Managing internal browning}

While small amounts of IB developed in early harvested Fuji apples stored at high $\mathrm{CO}_{2}$ levels, severe IB only developed in late-harvested apples of high maturity. In the 3 years of the study, fruit harvested earlier than $180 \mathrm{DAB}$ developed very little IB in storage, even at very high $\mathrm{CO}_{2}$ levels.

Fuji apples must develop a minimum amount of external red color to be accepted in increasingly competitive domestic and export markets. Under the warm temperature conditions that prevail prior to harvest in most

\begin{tabular}{|c|c|c|c|c|c|}
\hline $\begin{array}{l}\text { Harvest } \\
\text { date }\end{array}$ & $\begin{array}{l}\text { Days } \\
\text { after } \\
\text { bloom }\end{array}$ & $\begin{array}{c}\text { Flesh } \\
\text { firmness* }\end{array}$ & $\begin{array}{l}\text { Soluble } \\
\text { solids }\end{array}$ & $\begin{array}{c}\text { Titratable } \\
\text { acidity }\end{array}$ & $\begin{array}{c}\text { Starch } \\
\text { disappearance } \\
\text { score } \dagger\end{array}$ \\
\hline & & lb force & $\%$ & $\%$ & 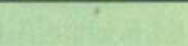 \\
\hline \multicolumn{6}{|l|}{1992} \\
\hline $9 / 21$ & 174 & $15.1(0.4) \ddagger$ & 15.5 & NDß & ND \\
\hline $10 / 1$ & 184 & $14.3(0.2)$ & 15.0 & & \\
\hline $10 / 12$ & 195 & $13.0(0.2)$ & 14.4 & & \\
\hline $10 / 27$ & 210 & $13.4(0.2)$ & 15.5 & & \\
\hline \multicolumn{6}{|l|}{1993} \\
\hline $9 / 13$ & 169 & $16.4(0.4)$ & 13.2 & 0.30 & 4.1 \\
\hline 9/27 & 183 & $13.7(0.2)$ & 13.5 & 0.30 & 4.0 \\
\hline $10 / 11$ & 197 & $14.5(0.4)$ & 14.2 & 0.28 & 5.1 \\
\hline $10 / 25$ & 211 & & & & \\
\hline Interior & & $13.5(0.3)$ & 13.9 & 0.27 & 5.7 \\
\hline Exterior & & $12.4(0.3)$ & 15.3 & 0.29 & 5.6 \\
\hline \multicolumn{6}{|l|}{1994} \\
\hline \multicolumn{6}{|c|}{ Commercially harvested row } \\
\hline $9 / 26$ & 180 & $16.1(0.3)$ & 12.4 & 0.30 & 4.7 \\
\hline $10 / 6$ & 190 & $14.7(0.2)$ & 12.3 & 0.29 & 5.1 \\
\hline $10 / 21$ & 205 & $14.0(0.3)$ & 12.1 & 0.29 & 5.9 \\
\hline $11 / 1$ & 216 & $13.6(0.2)$ & 11.5 & 0.27 & 5.9 \\
\hline \multicolumn{6}{|c|}{ Sample harvested row } \\
\hline $9 / 21$ & 175 & $16.1(0.3)$ & 12.3 & 0.31 & 4.7 \\
\hline $10 / 6$ & 190 & $14.6(0.2)$ & 12.6 & 0.31 & 5.3 \\
\hline $10 / 21$ & 205 & $15.2(0.3)$ & 12.8 & 0.30 & 5.6 \\
\hline $11 / 1$ & 216 & $14.2(0.3)$ & 12.7 & 0.27 & 5.9 \\
\hline \multicolumn{6}{|c|}{ *All harvest maturity measurements were made after one-week storage @ $36^{\circ} \mathrm{F}$ in 1992 and 1 -day storage } \\
\hline
\end{tabular}


Fuji apple-producing districts of California, fruit usually reach ideal internal maturity before developing sufficient red color for market acceptance. Growers waiting for the best possible red color risk delaying harvest beyond the time considered optimal for eating quality and storage life. Our findings show that this delay may also affect fruit susceptibility to storage disorders.

Internal browning is thought to be caused by the accumulation of injurious levels of respiratory $\mathrm{CO}_{2}$ in fruit tissues. Factors that may contribute to high internal $\mathrm{CO}_{2}$ concentrations include high fruit-respiration rates induced by high temperatures; reduced rates of $\mathrm{CO}_{2}$ diffusion through the cortex, skin, or wax coatings applied to apples; and high $\mathrm{CO}_{2}$ in the atmosphere surrounding fruit during storage. A greater resistance to gas movement within more mature fruit may account for the increased incidence of injury to late-harvested fruit observed in our studies and in commercial practice.

We currently do not know when IB appears during storage or if controlled atmosphere oxygen level or storage temperature affects IB development. Further research is needed in these areas, and to identify indicators of fruit maturity that could be used to reliably predict IB susceptibility. From results of our studies to date, we suggest the following guidelines for minimizing IB in Fuji apples:

1. Begin and end harvest as early as possible. IB incidence and severity are low in fruit harvested before 180 days after bloom.

2. Sample, cut and inspect fruit for IB during harvest, especially in orchards with a history of this disorder.

3. Use CA storage only for earlyharvested fruit free of IB at harvest.

4. Keep $\mathrm{CO}_{2}$ levels in CA as far below $0.5 \%$ as possible.

5. Expedite handling and marketing of late-harvested lots.

J. Grant is UC Farm Advisor, San Joaquin County; B. Mitcham is Extension

Postharvest Pomologist, and B. Biasi is Staff Research Associate, Department of Pomology, UC Davis; and S. Chinchiolo, is Production Manager, Philip Chinchiolo $\mathcal{E}$ Sons, Escalon, California.

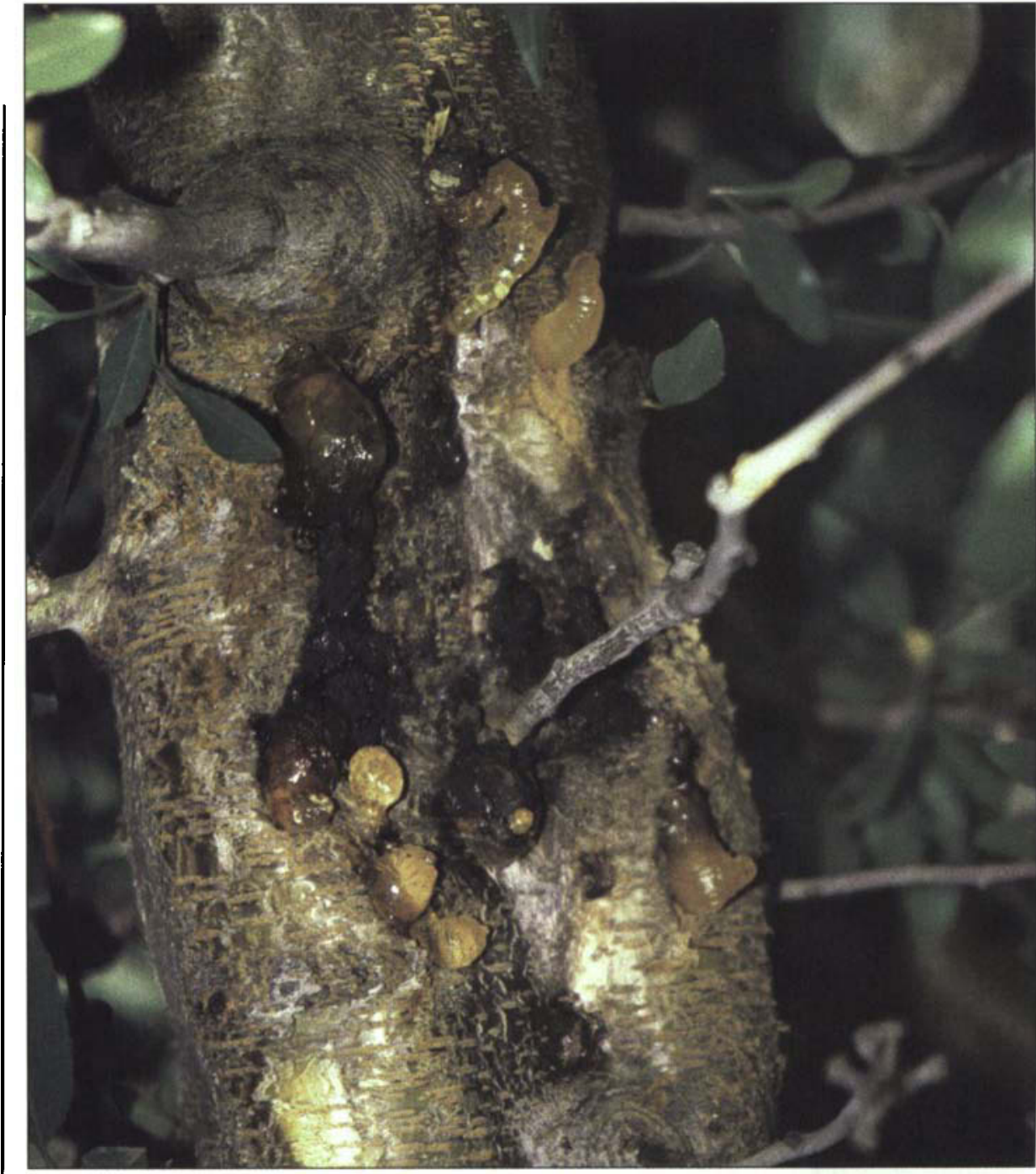

Ceratocystis cankers enlarge slowly over several years, with the margins of active cankers outlined by amber-colored gum balls. Infected limbs frequently die, but the disease seldom destroys the tree.

\title{
Almond pruning wounds, bark abrasions susceptible to Ceratocystis
}

\author{
Beth L. Teviotdale $\sqsupset$ Dennis M. Harper
}

In the past, pruning wounds were not regarded as potential infection sites. However, in a 2-year study, pruning cuts inoculated immediately or at intervals up to 14 days were found to be susceptible to Ceratocystis canker from September through February. Broken, dead or living twigs became infected throughout the year when inoculated with the fungus.
Ceratocystis canker, also known as mallet wound canker, is a fungus disease of stone fruit trees most commonly found on almond and, occasionally, prune trees. Highly susceptible almond cultivars include 'Mission,' 'Nonpareil' and 'Ne Plus Ultra.' The cankers are sunken, dark and perennial. They enlarge slowly over several years, with the margins of active cankers outlined by amber-colored gum balls. Infected limbs fre- 